\title{
Environmental and life cycle cost analysis of one switched reluctance motor drive and two inverter-fed induction motor drives
}

\author{
P. Andrada B. Blanqué E. Martínez J.I. Perat J.A. Sánchez M. Torrent \\ Grup d'Accionaments Elèctrics amb Commutació Electrònica (GAECE), EPS d'Enginyeria de Vilanova i la Geltrú, \\ Departament d'Enginyeria Elèctrica, Universitat Politècnica de Catalunya (UPC), Av. Victor Balaguer1, 08800 Vilanova i la \\ Geltrú, Spain \\ E-mail: pere.andrada@upc.edu
}

\begin{abstract}
Herein is described an environmental and life cycle cost (LCC) analysis of one switched reluctance motor (SRM) drive and two inverter-fed induction motor (IM) drives. The two types of drives are compared based on critical reasoning, and European Commission (EC) Regulation 640/2009 is considered. Environmental impact and LCC were evaluated according the Methodology for the Ecodesign of Energy-Using Products and accounting different operation conditions. The SRM drive was found to have less environmental impact than were the IM drives.
\end{abstract}

\section{Introduction}

In 2008, annual world consumption in primary energy was 12.267 Mtoe. Most (81\%) of this energy comes from fossil fuels [1]. Unbridled consumption of coal, oil and natural gas has accelerated the depletion of their deposits, increased atmospheric pollution and significantly contributed to global warming. Thus, to stop fossil fuel waste and consequences, energy conservation initiatives are urgently needed.

A major portion of consumed primary energy is converted to electrical energy. In industrialised countries, nearly twothirds of electrical energy is used to feed electric motors. In fact, in the European Union (EU) in 2005, energy consumption for electric motors during the use phase was $1067 \mathrm{TWh}$, corresponding to $427 \mathrm{Mt}$ of $\mathrm{CO}_{2}$ emissions [2]. According to predictions, unless limitations on energy consumption are enacted, motor energy consumption in the use phase is predicted to increase to 1252 TWh by 2020 . Therefore electric motors must be made more efficient, to enable energy savings and a reduction in emissions. Regulations establishing minimum efficiencies for electric motors have been created in the USA, Canada, Australia and, more recently, in the EU. Some associations - among the most important of which is NEMA - have defined a classification scheme for electric motors with higher efficiencies (premium efficiency motors).

Given the European context of the present work, the authors considered that a brief explanation on electric motors efficiency regulation in the EU would be apropos. The current European efficiency levels were adopted in a voluntary agreement supported by the European Committee of Manufacturers of Electrical Machines and Power
Electronics (CEMEP) and the European Commission (EC), based on testing methods and limits of acceptance defined under the IEC 60034-2: 1996 [3]. Regulation 640/2009 EC [4], implementing Directive 2005/32/EC, establishes ecodesign requirements for electric motors and variable speed drives in terms of energy efficiency levels. New efficiency levels were recently defined in standard IEC 60034$30: 2008$, based on the test methods and limits of acceptance indicated under IEC 60034-2-1:2007. Ecodesign requirements for electric motors will be applied according to the timetable shown in Table 1, which compares the CEMEP/EU agreement with Regulation 640/2009.

Although Regulation 640/2009 represents some progress in energy conservation, as it establishes ecodesign requirements for the placing on the market and for putting in service of electric motors, it addresses only the use phase (electricity consumption). However, focusing exclusively on consumption is no longer sufficient; energy savings initiatives must now account for all life cycle costs (LCC), including production, use and disposal. A useful tool for evaluating LCC is the Methodology for the Ecodesign of Energy-Using Products (MEEUP), which was developed to determine whether, and to what extent, a product meets the criteria stipulated in the Directive on the Ecodesign of Energy-Using Products (EuP 2005/32/EC).

Electric motors are usually identified with three-phase induction motors and variable speed drives with inverter-fed induction motor (IM) drives. Nevertheless, recently, there have been significant advances in the field of variable speed drives, in which the electric motor involved is not the threephase induction motor. These motors share one feature, unlike the three-phase induction motor; they can only be operated when they are associated with electronic control 


\section{wWw.ietdl.org}

The LCC considers all costs associated with the product: acquisition and installation costs; energy costs in the use phase; and repair and maintenance costs.

In the field of electric motors, MEEUP methodology has been used in the report for the EC: 'EUP lot 11 Motors', led by Dr A.T. de Almeida (University of Coimbra) [3].

\section{Description of the drives}

This paper focuses on environmental and LCC analysis of one SRM drive and two inverter-fed IM drives. Although SRM and IM are stator-magnetised motors, they have different constitution, whereas IM has a stator winding distributed in slots and a squirrel cage rotor, the SRM has a salient pole stator with concentrated windings and a salient pole rotor with no conductors or permanent magnets. An adequate indicator to compare different types of electrical machines is the torque per unit rotor volume that depends on the product of electric load and magnetic load. The magnetic load of SRM is lower than IM because of its salient pole structure. However its electric load is, generally, about twice that of IM. Therefore the torque per unit rotor volume of SRM is slightly higher than that of IM. To achieve the best comparison, the three motors were chosen with the same frame (IEC-90) and the drive systems were operated under the same conditions.

\subsection{SRM drive}

The SRM was an 8/6 SRM with $1.5 \mathrm{~kW}$ of output power and an IEC-90 frame (see Fig. 1). SRM voltage, $300 \mathrm{~V}$, was selected in order to match with common three-phase network of $230 \mathrm{~V}$ (line voltage) for better comparison with induction motor of 230/400 V. SRM was designed using the well-known FLUX 2D Finite Element package [13]; a sample of the design process is illustrated in Fig. 2, which shows flux plots in aligned and unaligned positions. Moreover, several ecodesign criteria were also considered during its design:

- the amount of materials should be minimised;

- the number of non-recyclable parts (i.e. plastics) should be minimised;

- the motor should be easy to assemble and disassemble;

- the windings should be easy to remove.

The SRM was built by the authors, but has not yet been commercialised.

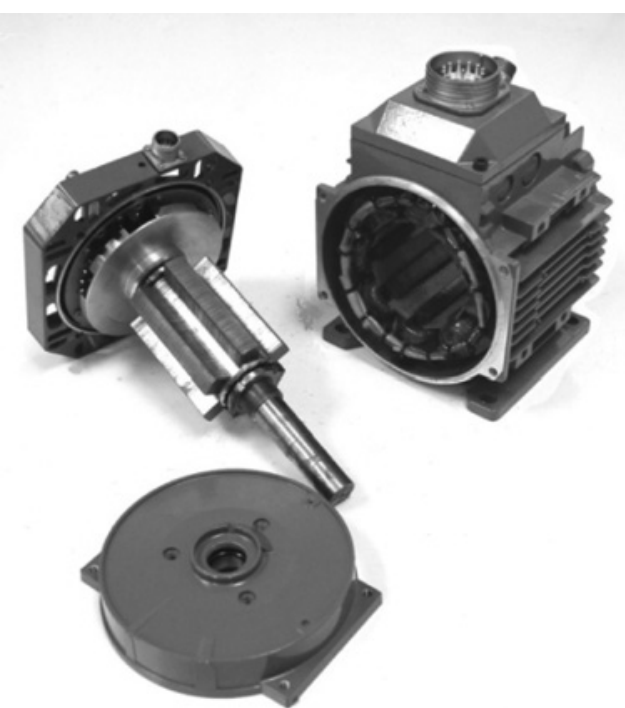

Fig. 1 Photograph of the 8/6 SRM disassembled

The SRM was controlled using the drive depicted in Fig. 3. The power converter is a four-phase, half asymmetric bridge (i.e. a classic converter), with two insulated gate bipolar transistors (IGBTs) and two fast diodes per phase. The rotor position is determined using an encoder or an ensemble comprising a slotted disk and three opto-interrupters placed inside the SRM. The speed controller, a proportionalintegral controller, generates a current command based on the error between the reference speed and the motor speed. The current in the appropriate phase is regulated at the reference current by hysteresis control. The firing angle calculator computes the turn-on and turn-off angles at every instant, accounting for the speed and reference current at the instant. The authors must point out that neither the SRM nor its controller were built to optimal efficiency.

\subsection{Inverter-fed IM motors}

The IMs had four poles, $230 / 400 \mathrm{~V}, 1.5 \mathrm{~kW}$ of output power and IEC-90 frame. The first was an Eff3, and the second an Eff1/IE2 (for more details, see the Appendix). Both motors were driven by an inverter-fed vector control in closed loop through an incremental encoder. The IMs and the vectorcontrol equipment were commercially available. The Eff3 IM was chosen to better appreciate the reduction in environmental impact obtained upon application of
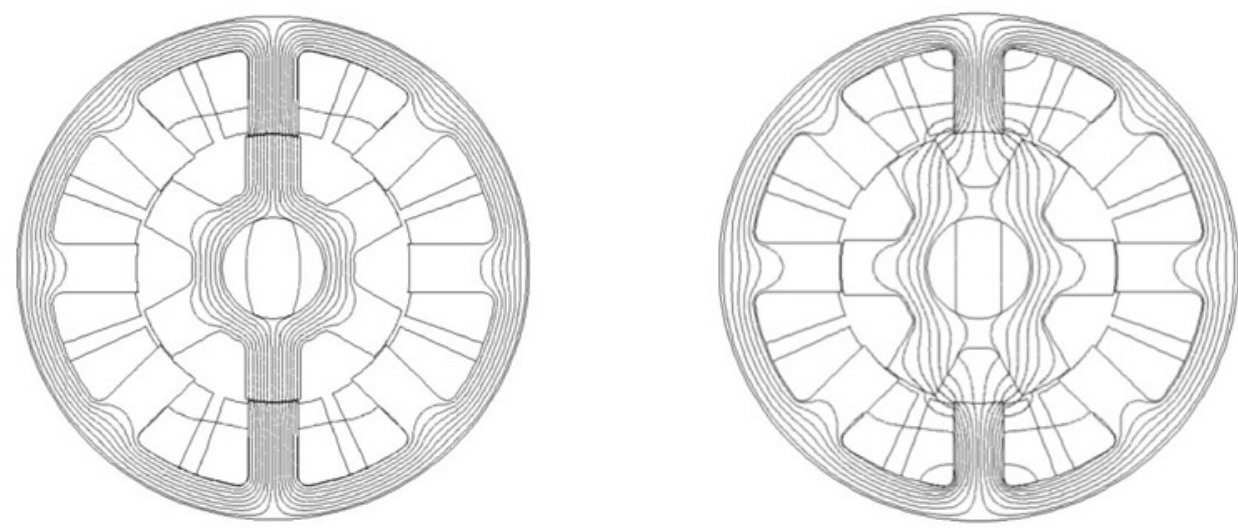

Fig. 2 Flux plots of the 8/6 SRM in aligned (left) and unaligned (right) positions, obtained using the FLUX 2D FEM package 


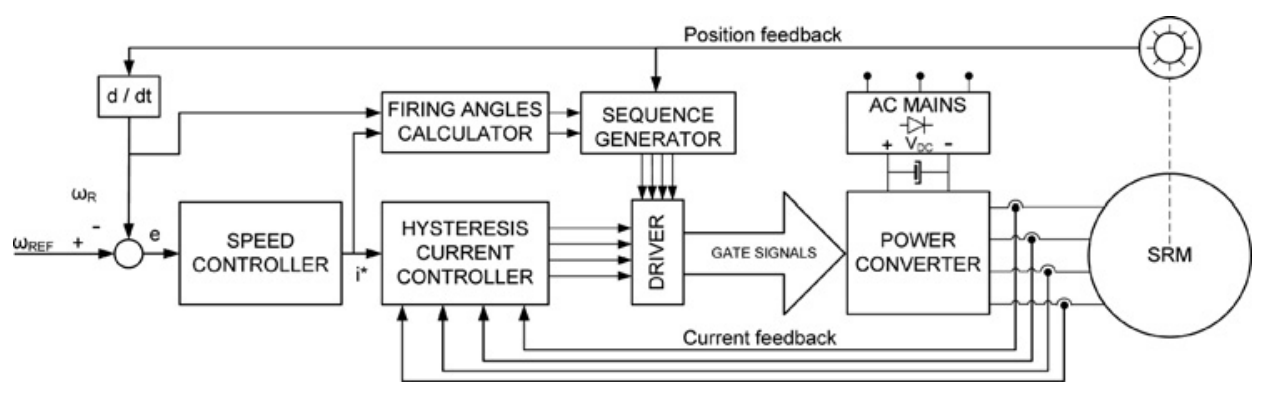

Fig. 3 Schematic diagram of the SRM drive

Regulation 640/2009. In contrast, the Eff1/IE2 IM was chosen because this type is expected to become the standard for IM drives in the European market within a few years [14].

\subsection{Measuring efficiency}

A DC motor coupled to a torque transducer was used to load the three drives. Global efficiency, ratio of mechanical power output to mains electrical power (including all the losses in the power converter stage), was determined for all drives. The input power (electrical power) was measured using a digital wattmeter (ZES Zimmer model LMG-450 four channels) and the output torque and speed by means of a torque transducer (HBM model T-34-10). The accuracy in per cent of the wattmeter is of $0.1 \%$ and the accuracy of torque and speed are of $0.1 \%$ for each ones. Therefore the accuracy of efficiency calculated by means of the quotient between mechanical power, product of torque $(\mathrm{N} \mathrm{m})$ per speed $(\mathrm{rad} / \mathrm{s})$ and electrical power is of $0.3 \%$. This is a good accuracy that will have no influence in the results of LCC. For each, drive torque was plotted against global efficiency at different speeds: see Fig. 4 for the SRM drive; Fig. 5 for the Eff1/IE2 IM drive and Fig. 6, for the Eff3 IM drive.

\section{Environmental impact and LCC}

The environmental impact and LCC of the three studied drives were evaluated using MEEUP methodology. This section first covers the study data (inputs), which were collected including materials, energy use and economic data for each life stage and for each drive. Translation of these inputs into quantifiable environmental impacts is then

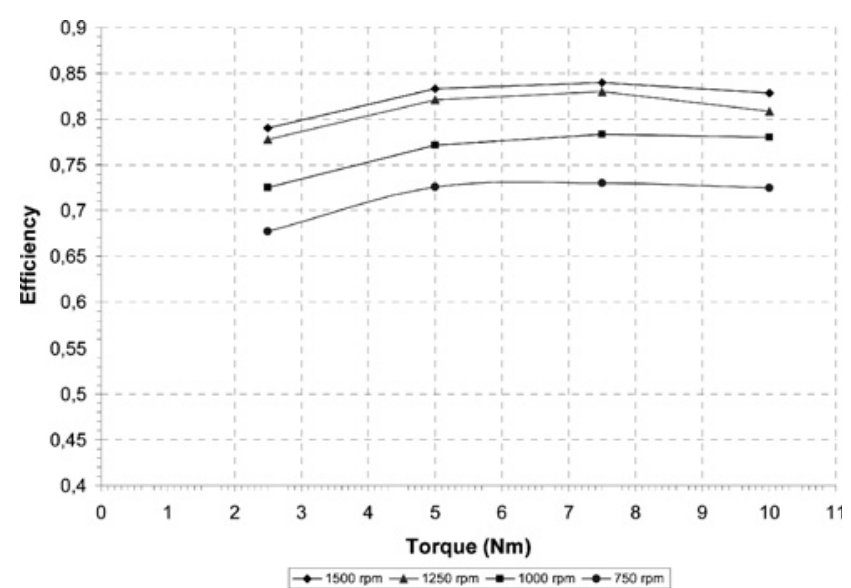

Fig. 4 Global efficiency against torque for the SRM drive

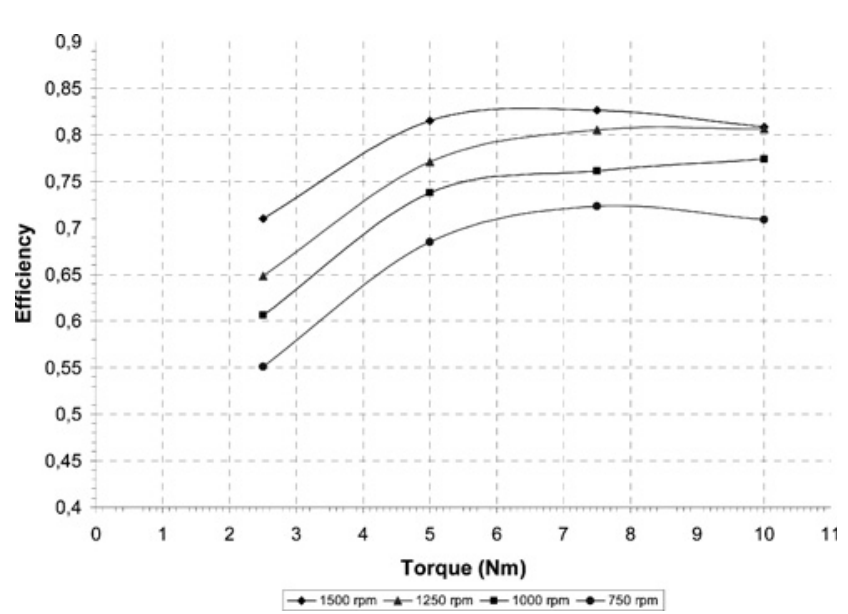

Fig. 5 Global efficiency against torque for the Eff1/IE2 IM drive

discussed. Subsequently, to complete the environmental study, an analysis of the noise level of the different drives is also performed. Finally, an evaluation of the LCC related with the drives is presented.

\subsection{Inputs}

The material composition of the drives, based on the bill of materials (including packaging), is listed in Table 2. The content of materials is a key issue in the analysis of LCC and it depends on the type of drive. Consequently, given the different constitution of the drives studied and in order to better understand the final results, it is appropriate to briefly analyse the values of Table 2 . Although the motor

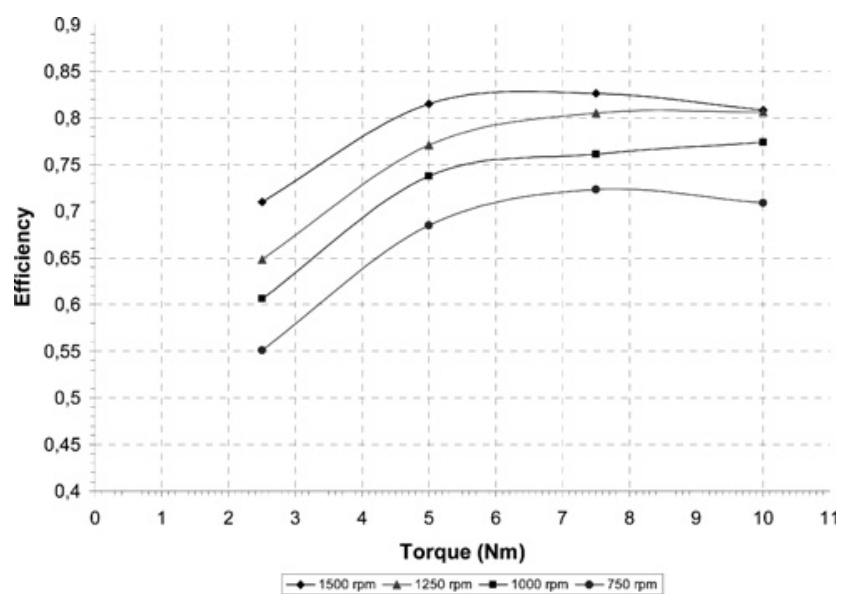

Fig. 6 Global efficiency against torque for the Eff3 IM drive 
Table 2 Bill of materials of each drive

\begin{tabular}{lccc}
\hline Material, kg & Eff3 IM & Eff1/IE2 IM & $8 / 6$ SRM \\
\hline electrical steel & 7.84 & 8.65 & 7.46 \\
other steel & 2.18 & 1.73 & 1.51 \\
aluminium & 5.13 & 5.28 & 4.48 \\
copper & 1.80 & 2.05 & 2.50 \\
insulation material & 0.07 & 0.07 & 0.01 \\
impregnation resin & 0.44 & 0.44 & 0.20 \\
paint & 0.06 & 0.06 & 0.06 \\
plastics & 0.39 & 0.39 & 0.56 \\
electronics & 0.29 & 0.29 & 0.42 \\
packing material & 1.50 & 1.50 & 1.50 \\
\hline
\end{tabular}

case is of aluminium in the three motors, aluminium weight is higher in IMs because of their squirrel cage rotor. Electric steel, insulation material and impregnation resin weight are higher in IMs as consequence of the small surface of the slots and their distributed stator winding. Instead, copper weight is higher in SRM because of its higher electric load. Plastics and electronics weight are also higher in SRM because its power converter has four phases and therefore requires more components.

In an attempt to mimic the real behaviour of the drives in their use phase, three cases with different operating conditions were considered. The lifetime, the number of operating hours, the load factor and the speed (with its corresponding efficiency) for each case have been compiled in Table 3.

\subsection{Environmental impact}

The environmental impacts in the production, distribution and end-of-life phase for each drive and for the different considered cases were calculated using the spreadsheet of MEEUP and they are shown in Table 4.

Table 5 lists the environmental impacts in the use phase for the three drives and Table 6 shows the total environmental impacts for the three studied cases. To better visualise the comparison of the environmental impact of each drive, some of their respective impacts were graphed for each set of operating conditions (see Figs. 7-9). These graphs show the normalised influence of eight leading environmental indicators for each drive, relative to Eff3 IM (assigned a

Table 3 Operating conditions in the use phase

\begin{tabular}{lccccc}
\hline Variable & Case 1 & & Case 2 & Case 3 \\
\hline Lifetime, years & 12 & 1000 & 12 & 12 & 2000 \\
operating hours & 4000 & 50 & 100 & 2000 & 75 \\
load factor, \% & 75 & 1000 & 1000 & 1000 & 750 \\
speed, rpm & 1500 & 0.628 & 0.686 & 0.668 & 0.622 \\
efficiency IM (Eff3) & 0.750 & 0.737 & 0.774 & 0.761 & 0.723 \\
efficiency IM (Eff1/IE2) & 0.826 & 0.771 & 0.780 & 0.783 & 0.730 \\
efficiency 8/6 SRM & 0.840 & & & 0.805 \\
\hline
\end{tabular}

Table 4 Environmental impacts in the production, distribution and end-of-life phases for each drive

\begin{tabular}{|c|c|c|c|c|c|c|c|}
\hline \multirow[t]{2}{*}{ Main indicators } & \multicolumn{3}{|c|}{ Production } & \multirow{2}{*}{$\begin{array}{l}\text { Distribution } \\
\text { All the motors }\end{array}$} & \multicolumn{3}{|c|}{ End-of-life } \\
\hline & Eff3 IM & Eff1/IE2 IM & 8/6 SRM & & Eff3 IM & Eff1/IE2 IM & 8/6 SRM \\
\hline total energy GER ${ }^{\mathrm{a}}(\mathrm{MJ})$ & 1373 & 1452 & 1435 & 88 & 67 & 70 & 60 \\
\hline of which, electricity (in primary MJ) & 292 & 301 & 314 & 0 & -8 & -8 & -11 \\
\hline water process (I) & 132 & 133 & 169 & 0 & -7 & -7 & -10 \\
\hline water cooling (I) & 368 & 372 & 290 & 0 & -3 & -3 & -4 \\
\hline waste, non-hazardous landfill, g & 57011 & 63246 & 69483 & 69 & 1092 & 1138 & 1023 \\
\hline waste, hazardous incinerated, $\mathrm{g}$ & 348 & 348 & 455 & 1 & 868 & 868 & 803 \\
\hline \multicolumn{8}{|l|}{ Emissions to air } \\
\hline greenhouse gases in $\mathrm{GWP} 100^{\mathrm{b}}\left(\mathrm{kg} \mathrm{CO}_{2}\right.$ eq) & 86 & 91 & 88 & 7 & 5 & 6 & 5 \\
\hline acidification potential $\left(\mathrm{g} \mathrm{SO}_{2}\right.$ eq) & 937 & 1023 & 1174 & 19 & 8 & 9 & 5 \\
\hline $\operatorname{VOC}(g)^{c}$ & 3 & 3 & 3 & 1 & 0 & 0 & 0 \\
\hline $\operatorname{POP}\left(\right.$ ng l-Teq) ${ }^{d}$ & 432 & 456 & 395 & 0 & 8 & 8 & 7 \\
\hline heavy metals (mg Ni eq) & 222 & 243 & 266 & 4 & 33 & 34 & 31 \\
\hline PAHs $(m g ~ N i ~ e q))^{\mathrm{e}}$ & 103 & 107 & 96 & 4 & -1 & -1 & -1 \\
\hline particulate matter, g & 74 & 77 & 70 & 93 & 158 & 161 & 147 \\
\hline \multicolumn{8}{|l|}{ Emissions to water } \\
\hline heavy metals, mg Hg/20 & 80 & 85 & 82 & 0 & 6 & 6 & 4 \\
\hline eutrophication, $\mathrm{g} \mathrm{PO}_{4}$ & 8 & 8 & 6 & 0 & 1 & 1 & 0 \\
\hline
\end{tabular}

${ }^{\mathrm{a}} \mathrm{Gross}$ energy requirement

${ }^{\mathrm{b}} \mathrm{Global}$ warming potential

${ }^{c}$ Volatile organic compounds

${ }^{\text {dPersistent }}$ organic pollutants

ePolycyclic aromatic hydrocarbon 
Table 5 Environmental impact in the use phase for each drive

\begin{tabular}{|c|c|c|c|c|c|c|c|c|c|}
\hline \multirow[t]{2}{*}{ Main indicators } & \multicolumn{3}{|c|}{ Case 1} & \multicolumn{3}{|c|}{ Case 2} & \multicolumn{3}{|c|}{ Case 3} \\
\hline & Eff3 IM & Eff1/IE2IM & $8 / 6 \mathrm{SRM}$ & Eff3 IM & Eff1/IE2 IM & $8 / 6 \mathrm{SRM}$ & Eff3 IM & Eff1/IE2 IM & $8 / 6 \mathrm{SRM}$ \\
\hline total energy GER ${ }^{(a)}(\mathrm{MJ})$ & 189434 & 119933 & 108945 & 285633 & 180186 & 161990 & 272700 & 178529 & 164517 \\
\hline of which, electricity (in primary $\mathrm{MJ}$ ) & 188701 & 119199 & 108212 & 283433 & 177984 & 159790 & 271234 & 177061 & 163050 \\
\hline water process (I) & 12581 & 7948 & 7216 & 18899 & 11869 & 10657 & 18085 & 11806 & 10873 \\
\hline water cooling (I) & 503198 & 317860 & 288560 & 755810 & 474612 & 426090 & 723282 & 472155 & 434790 \\
\hline waste, non-hazardous landfill, g & 219355 & 138834 & 126157 & 330326 & 208251 & 187341 & 315614 & 206551 & 190430 \\
\hline $\begin{array}{l}\text { waste, hazardous incinerated, } \mathrm{g} \\
\text { Emissions to air }\end{array}$ & \multicolumn{8}{|c|}{ Emissions to air } & 3766 \\
\hline Greenhouse gases in GWP100 ${ }^{(b)}\left(\mathrm{kg} \mathrm{CO}_{2}\right.$ eq) & 8291 & 5258 & 4779 & 12539 & 7937 & 7143 & 11950 & 7840 & 7229 \\
\hline acidification potential, $\mathrm{g} \mathrm{SO}_{2}$ eq & 48655 & 30759 & 27931 & 73177 & 46027 & 41346 & 69972 & 45724 & 42119 \\
\hline VOC, $g^{(\mathrm{c})}$ & 83 & 57 & 52 & 142 & 102 & 95 & 126 & 90 & 85 \\
\hline POP, ng I-Teq ${ }^{(d)}$ & 1241 & 786 & 713 & 1871 & 1180 & 1059 & 1786 & 1170 & 1077 \\
\hline heavy metals, mg Ni eq & 3396 & 2203 & 2015 & 5337 & 3529 & 3217 & 4970 & 3354 & 3115 \\
\hline PAHs, mg Ni eq ${ }^{(e)}$ & 529 & 392 & 370 & 1029 & 822 & 786 & 848 & 663 & 635 \\
\hline particulate matter, $\mathrm{g}$ & 3685 & 3302 & 3242 & 9499 & 8919 & 8819 & 6785 & 6267 & 6190 \\
\hline \multicolumn{10}{|l|}{ Emissions to water } \\
\hline heavy metals, mg Hg/20 & 1217 & 769 & 699 & 1830 & 1150 & 1033 & 1750 & 1143 & 1053 \\
\hline eutrophication, $\mathrm{g} \mathrm{PO}_{4}$ & 6 & 4 & 3 & 9 & 6 & 5 & 9 & 6 & 5 \\
\hline
\end{tabular}

Table 6 Environmental impacts for each drive (total)

\begin{tabular}{|c|c|c|c|c|c|c|c|c|c|}
\hline \multirow[t]{2}{*}{ Main indicators } & \multicolumn{3}{|c|}{ Case 1} & \multicolumn{3}{|c|}{ Case 2} & \multicolumn{3}{|c|}{ Case 3} \\
\hline & Eff3 IM & Eff1/IE2IM & 8/6 SRM & Eff3 IM & Eff1/IE2IM & 8/6 SRM & Eff3 IM & Eff1/IE2 IM & 8/6 SRM \\
\hline total energy GER ${ }^{(a)}(\mathrm{MJ})$ & 190962 & 121543 & 110528 & 287161 & 181796 & 163573 & 274228 & 180139 & 166100 \\
\hline of which, electricity (in primary MJ) & 188984 & 119492 & 108516 & 283717 & 178277 & 160094 & 271517 & 177354 & 163354 \\
\hline water process (I) & 12706 & 8073 & 7375 & 19024 & 11994 & 10816 & 18210 & 11932 & 11032 \\
\hline water cooling (I) & 503563 & 318229 & 288846 & 756175 & 474981 & 426377 & 723647 & 472524 & 435076 \\
\hline waste, non-hazardous landfill, g & 277526 & 203287 & 196732 & 388498 & 272704 & 257916 & 373786 & 271004 & 261005 \\
\hline $\begin{array}{l}\text { waste, hazardous incinerated, g } \\
\text { Emissions to air }\end{array}$ & 5569 & 3968 & 3757 & 7759 & 5329 & 4954 & 7474 & 5305 & 5025 \\
\hline $\begin{array}{l}\text { greenhouse gases in } \\
\text { GWP100, }{ }^{(b)} \mathrm{kg} \mathrm{CO}_{2} \text { eq }\end{array}$ & 8389 & 5362 & 4879 & 12636 & 8040 & 7243 & 12048 & 7944 & 7328 \\
\hline acidification potential, $\mathrm{g} \mathrm{SO}_{2}$ eq & 49618 & 31810 & 29130 & 74141 & 47077 & 42545 & 70935 & 46774 & 43317 \\
\hline VOC, $g^{(\mathrm{c})}$ & 86 & 60 & 56 & 145 & 106 & 99 & 129 & 94 & 88 \\
\hline POP, ng I-Teq ${ }^{(d)}$ & 1681 & 1250 & 1115 & 2311 & 1644 & 1461 & 2226 & 1634 & 1479 \\
\hline heavy metals, mg Ni eq & 3654 & 2484 & 2316 & 5596 & 3809 & 3518 & 5228 & 3635 & 3415 \\
\hline PAHs, mg Ni eq ${ }^{(e)}$ & 635 & 502 & 469 & 1136 & 932 & 885 & 955 & 773 & 734 \\
\hline particulate matter, g & 4008 & 3633 & 3552 & 9823 & 9250 & 9129 & 7109 & 6598 & 6500 \\
\hline Emissions to water & & & & & & & & & \\
\hline heavy metals, mg Hg/20 & 1304 & 861 & 784 & 1916 & 1241 & 1118 & 1837 & 1234 & 1138 \\
\hline eutrophication, $\mathrm{g} \mathrm{PO}_{4}$ & 14 & 12 & 10 & 17 & 14 & 11 & 17 & 14 & 11 \\
\hline
\end{tabular}

value of 1). These eight environmental indicators were: total energy (GER), water (process), water non-hazardous landfill, greenhouse gases in GWP100, acidification emissions, heavy metals, PM and eutrophication.

\subsection{Analysis of noise level}

Although noise is not an environmental indicator in MEEUP methodology, it seems appropriate to carry out an analysis of the noise level in the considered drives. The average sound power $\left(L_{\mathrm{wA}}\right)$ and the average sound pressure $\left(L_{\mathrm{pA}}\right)$ were measured in full load conditions (load factor 100\%) and $1500 \mathrm{rpm}$ for the three drives, the results obtained are listed in Table 7. The average sound pressure was measured at $1 \mathrm{~m}$ of distance from the machine surface.

\subsection{Life cycle costs}

Table 8 summarises the LCC for each drive. LCC, according to MEEUP methodology, is the sum of purchase and installation costs; energy costs in the use phase; and repair and maintenance costs. The energy costs in the use phase are electrical energy costs. The electric drives are not enduse devices; they are energy converters thus only the energy because of losses is consumed inside the drive therefore only this energy must be considered in the LCC, the rest of the absorbed energy is transformed into mechanical power. The electrical energy costs were calculated based on current electricity rates in Spain. The product list price for each IM drive (including the costs of motor, vector control equipment and encoder) is considered, whereas that of the $\mathrm{SRM}$ drive is just an estimate. The repair and maintenance 


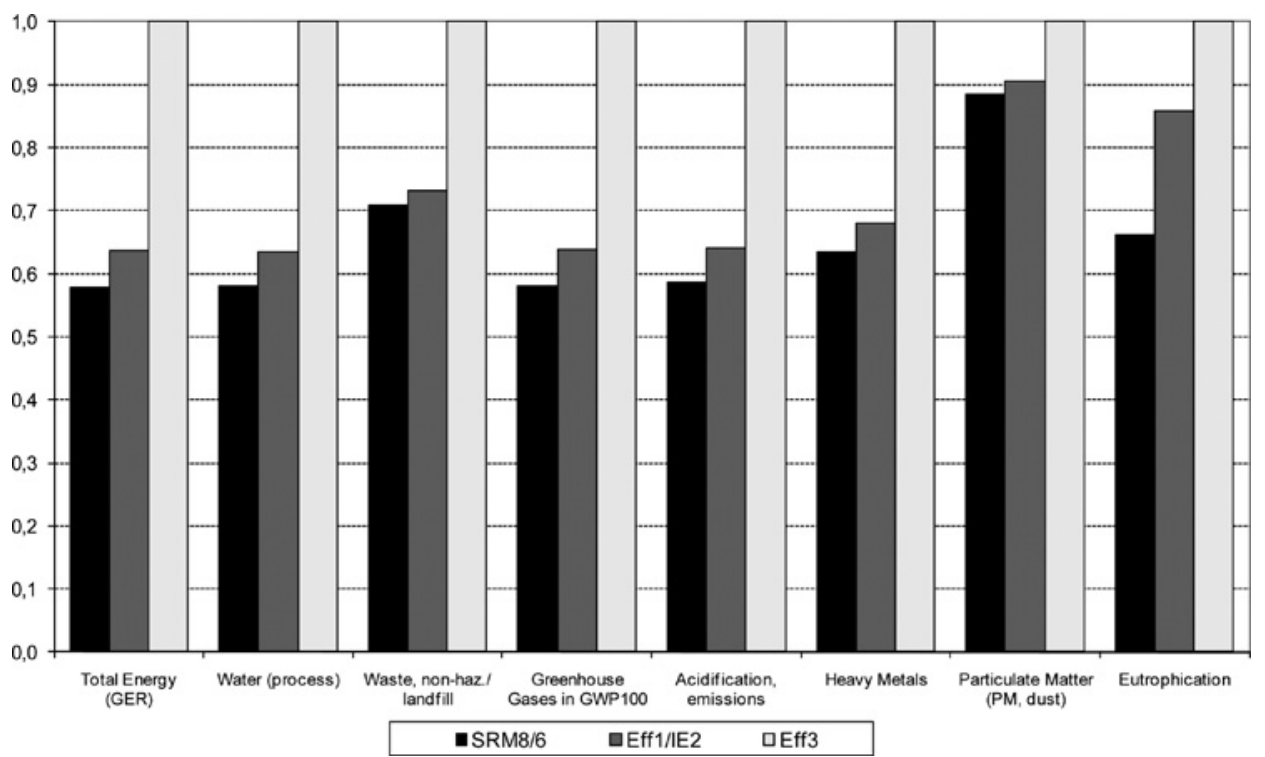

Fig. 7 Graph of eight major environmental impacts for each drive in case 1 (values normalised to those of Eff3 IM, set at 1)

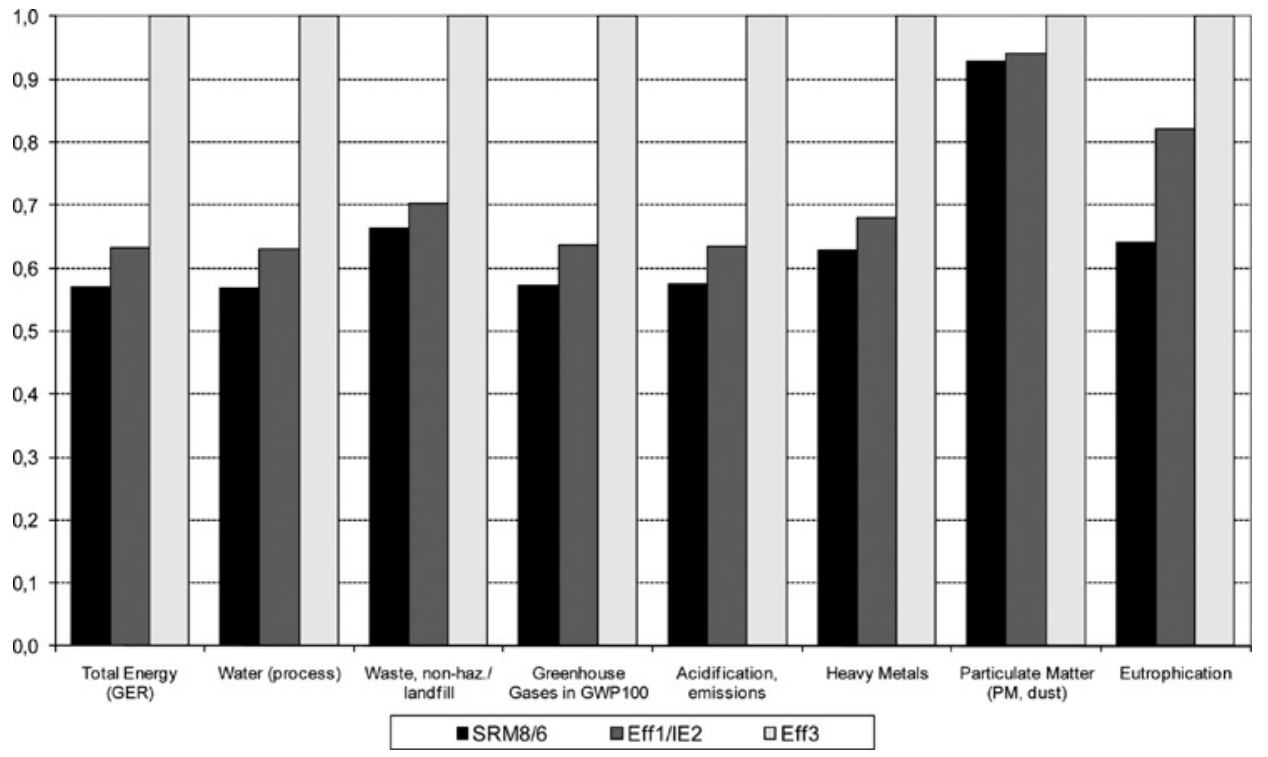

Fig. 8 Graph of eight major environmental impacts for each drive in case 2 (values normalised to those of Eff3 IM, set at 1)

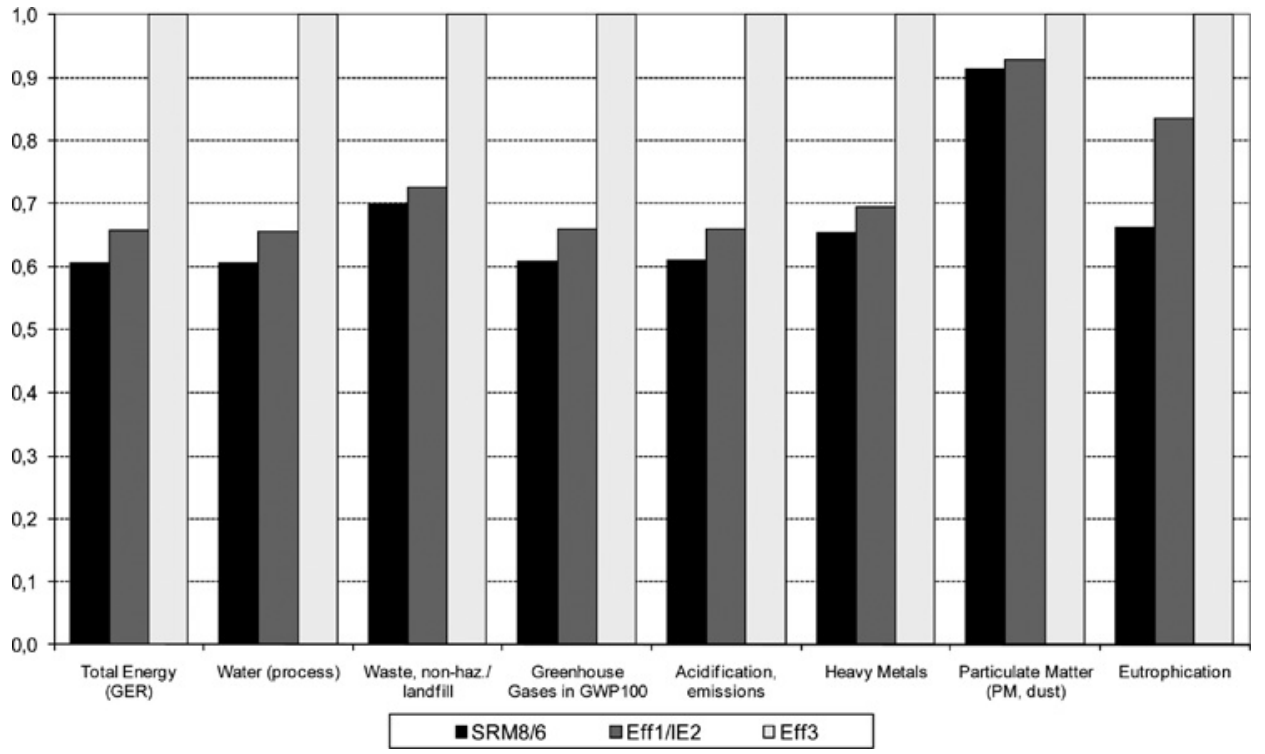

Fig. 9 Graph of eight major environmental impacts for each drive in case 3 (values normalised to those of Eff3 IM, set at 1) 
Table 7 Average sound power $\left(L_{\mathrm{wA}}\right)$ and the average sound pressure $\left(L_{p A}\right)$ of the three drives

\begin{tabular}{lcc}
\hline & $L_{w A}, d B(A)$ & $L_{p A}, d B(A)$ \\
\hline Eff3 IM & 84 & 73 \\
Eff1/IE2 IM & 88 & 77 \\
8/6 SRM & 100 & 89 \\
\hline
\end{tabular}

Table 8 Life cycle costs

\begin{tabular}{lccc}
\hline & Eff3 IM & Eff1/IE2 IM & $8 / 6$ SRM \\
\hline $\begin{array}{l}\text { product list price, } € \\
\text { energy costs, } €\end{array}$ & 1281 & 1425 & 1542 \\
case 1 & 1982 & 1252 & 1137 \\
case 2 & 2978 & 1870 & 1679 \\
case 3 & 2849 & 1860 & 1713 \\
repair and maintenance costs & - & - & - \\
life cycle cost LCC, $€$ & & & \\
case 1 & 3263 & 2677 & 2679 \\
case 2 & 4259 & 3295 & 3221 \\
sase 3 & 4130 & 3285 & 3255 \\
\hline
\end{tabular}

costs were considered negligible because drives having a power of $5 \mathrm{~kW}$ or less are not typically repaired upon failure.

For a better comparison between machines with different efficiencies and different initial costs, payback period (PP) and net present value (NPV) were determined, Table 9. Both terms were calculated for the Eff1/IE2 IM drive and 8/6 SRM drive against the Eff3 IM drive for the different cases considered. It is important to point out that the per year energy savings (first two columns of Table 9) were computed by means of the values of Table 3, considering the difference between the cost of absorbed electrical energy of the drives in comparison at each case. The NPV was obtained in all the cases with a discount rate of $4 \%$ and considering a period of time equal to the lifetime of the drives, 12 years.

\subsection{Discussion}

As indicated by Table 4 , in the production phase, the SRM drive scores higher in all the environmental indicators than do the IM drives, whereas in the end-of-life phase, the opposite is true for most of the indicators (except electricity, water process and water cooling); obviously, in the distribution phase, the drives all score equally. Better results for the SRM could surely have been obtained if a three-phase SRM had been evaluated instead of a fourphase one, as it would require less electronics components and plastics.
Table 5 shows the environmental impacts in the use phase, in which the SRM drive scores better than both IM drives in all the three cases considered. This is due to its superior efficiency in all the ranges, especially at light loads. As corroborated by the overall results compiled in Table 6 and in Figs. 7-9, the SRM drive shows lower environmental impact than the considered IM drives in all the studied cases. The noise analysis confirms what is well known, SRM drive is noisier than IM drives. Furthermore, the LCC analysis indicates that the SRM drive has lower electricity costs in all cases. However, its total costs are not as favourable, even in case 1, the Eff1/ IE2 IM drive implies lower costs, because of SRM drives have not yet become the status of standard commodity, and therefore have a higher list price. One of the main reasons for this fact is the lack of specific power modules for SRM. In this sense, it is not surprising that the PP of SRM drives is longer, for all the cases, than those of Eff1/IE2 IM drives. Nevertheless, it is well known that simple payback calculation, PP, ignores the value of money and therefore if it has to be taken into account NPV is a better indicator. Table 8 shows that the values of NPV are clearly in favour of SRM drive except for the case 1 .

It could argue that if an IE3 IM had been evaluated in this study, it would have shown better results than the SRM in environmental terms. However, in that case, for a fair comparison, a SRM drive with optimised efficiency would have to be used.

This study was carried out using MEEUP methodology, which has proven to be a simple methodology that gives good results, especially for the use phase. One drawback of MEEUP methodology is that it does not reflect very well some of the main advantages of SRM drives, namely, the ease of disassembly in the end-of-life phase.

In this investigation the drives considered were rated at $1.5 \mathrm{~kW}$ of output power that can be considered representative of the low power range. Further studies should be carried out in drives of medium and high power in order to complete this research.

\section{Conclusion}

The environmental impacts and LCC of one SRM drive and two inverter-fed IM drives have been analysed. This study takes into account EC Regulation 640/2009, and was performed using MEEUP methodology, considering different operating conditions. In all the studied cases, the SRM drive shows lower environmental impact than do the IM drives. Therefore lower environmental impact is yet another feature to add to the list of advantages of SRM drives, and should be considered when comparing SRM and IM drives.

Table 9 Payback period and net present value

\begin{tabular}{ccccccc}
\hline & $\begin{array}{c}\text { Energy savings } \\
\text { Eff1/IE2 IM against } \\
\text { Eff3 IM, kWh/year }\end{array}$ & $\begin{array}{c}\text { Energy savings } \\
\text { 8/6 SRM against } \\
\text { Eff3 IM, kWh/year }\end{array}$ & $\begin{array}{c}\text { PP Eff1/IE2 IM against } \\
\text { Eff3 IM, years }\end{array}$ & $\begin{array}{c}\text { PP 8/6 SRM against } \\
\text { Eff3 IM, years }\end{array}$ & $\begin{array}{c}\text { NPV Eff1/IE2 IM } \\
\text { against Eff3 IM, } €\end{array}$ & $\begin{array}{c}\text { NPV 8/6 SRM } \\
\text { against Eff3 IM, € }\end{array}$ \\
\hline case 1 & 552 & 639 & 2.1 & 3.3 & 504 & 489 \\
case 2 & 837 & 981 & 1.4 & 2.1 & 839 & 734 \\
case 3 & 748 & 857 & 1.5 & 2.4 & 747 \\
\hline
\end{tabular}




\section{Acknowledgments}

This research was supported by the Spanish Ministry of Education and Science and the ERDF (DPI2006-09880).

\section{References}

1 'Key world energy statistics' (International Energy Agency, 2010)

2 Binder, A.: 'Potentials for energy savings with modern drive technology: a survey'. SPEDAM, 2008, pp. 90-95

3 de Almeida, A.T., Ferreira, F.J.T.E., Fong, J., Fonseca, P.: 'EUP Lot 11 motors: final'. February 2008

4 Commission Regulation (EC) No. 640/2009 of 27 July 2009 implementing Directive 2005/327 EC of the European Parliament and of the Council with regard to ecodesign requirements for electric motors. Official Journal of the European Union; 23.7.2009

5 de Ameida, A.T., Ferreira, F.J.T.E., Fong, J.A.C.: 'Standards for efficiency of electric motors, permanent magnet synchronous motor technology', IEEE Ind. Appl. Mag., 2011, 17, (1), pp. 12-19

6 Lawrenson, P.J., Stephenson, J.M., Blenkinsop, P.T., Corda, J., Fulton, N.N.: 'Variable speed switched reluctance motors'. Proc. IEE, July 1980, vol. 127 , pt. B, no 4, pp. 253-265

7 Mogbelli, H., Adams, G.E., Hoft, R.G.: 'Performance of a 10-HP switched reluctance motor and comparison with induction motor', IEEE Trans. Ind. Appl., 1991, 27, (3), pp. 531-538

8 Turner, M.J., Young, P.Y.P., Wallace, R.S.: 'Comparing European 132 frame switched reluctance and induction motor drives', IECON, 1997, 2 , pp. $403-408$

9 Binder, A.: 'Switched reluctance drive and inverter-fed induction machine: a comparison of design parameters and drive performance', Electr. Eng, 2000, 82, pp. 239-248

10 Martínez, E., Andrada, P., Blanqué, B., Torrent, M., Perat, J.I., Sánchez, J.A.: 'Environmental and life cycle cost analysis of a switched reluctance motor'. ICEM 2008, CD-ROM, 6-9 September 2008 Vilamoura, Portugal

11 Andrada, P., Blanqué, B., Martínez, E., Perat, J.I., Sánchez, J.A., Torrent, M.: 'Comparison of environmental and life cycle impact of a switched reluctance motor drive and inverter-fed induction motor drives'. Int. Conf. Renewable Energies and Power Quality (ICREPQ'09), Valencia, Spain, 15-17 April 2009

12 MEEUP Methodology report, Final 2005, VHK for European Commission. ec.europa.eu/energy/demand/.../2005_11_28_final report1_en.pdf
13 FLUX User's manual. www.cedrat.com

14 Jardot, D., Eichhammer, W., Fleiter, T.: 'Effects of economies of scale and experience on the costs of energy-efficient technologies- case of study of electric motors in Germany', Energy Efficiency, 2010, 3, pp. $331-346$

\section{Appendix}

SRM and IMs nameplate data are shown in Table 10.

Main data for vector control equipment:

PDL electronics

Microdrive Elite ME-6.5

Closed loop vector control

Input voltage: $230 \mathrm{Vac} 3$ phase

Frequency range: $0-100 \mathrm{~Hz}$

Efficiency (full load, $50 \mathrm{~Hz}$ ): $>97 \%$

Output current: $6.5 \mathrm{~A}$

Insulation class: IP54

Table 10 SRM and IMs nameplate data

\begin{tabular}{lccc}
\hline & $8 / 6$ SRM & Eff3 IM & Eff1/IE2 IM \\
\hline frame size & $90 \mathrm{~L}$ & $90 \mathrm{~L}$ & $90 \mathrm{~L}$ \\
power, $\mathrm{kW}$ & 1.5 & 1.5 & 1.5 \\
speed, rpm & 1500 & 1420 & 1440 \\
voltage & $300 \mathrm{~V} \mathrm{DC}^{\mathrm{a}}$ & $230 / 400 \mathrm{~V}$ & $230 / 400 \mathrm{~V}$ \\
current, A & $5,8^{\mathrm{b}}$ & $6.1 / 3.5$ & $5.7 / 3.3$ \\
power factor & - & 0.8 & 0.77 \\
IP & $\mathrm{IP55}$ & $\mathrm{IP5} 55$ & $\mathrm{IP55}$ \\
insulation class & $\mathrm{F}$ & $\mathrm{F}$ & $\mathrm{F}$ \\
\hline
\end{tabular}

${ }^{a} 230 \mathrm{~V}$ AC mains

${ }^{\mathrm{b}} \mathrm{RMS}$ value, hysteresis control 